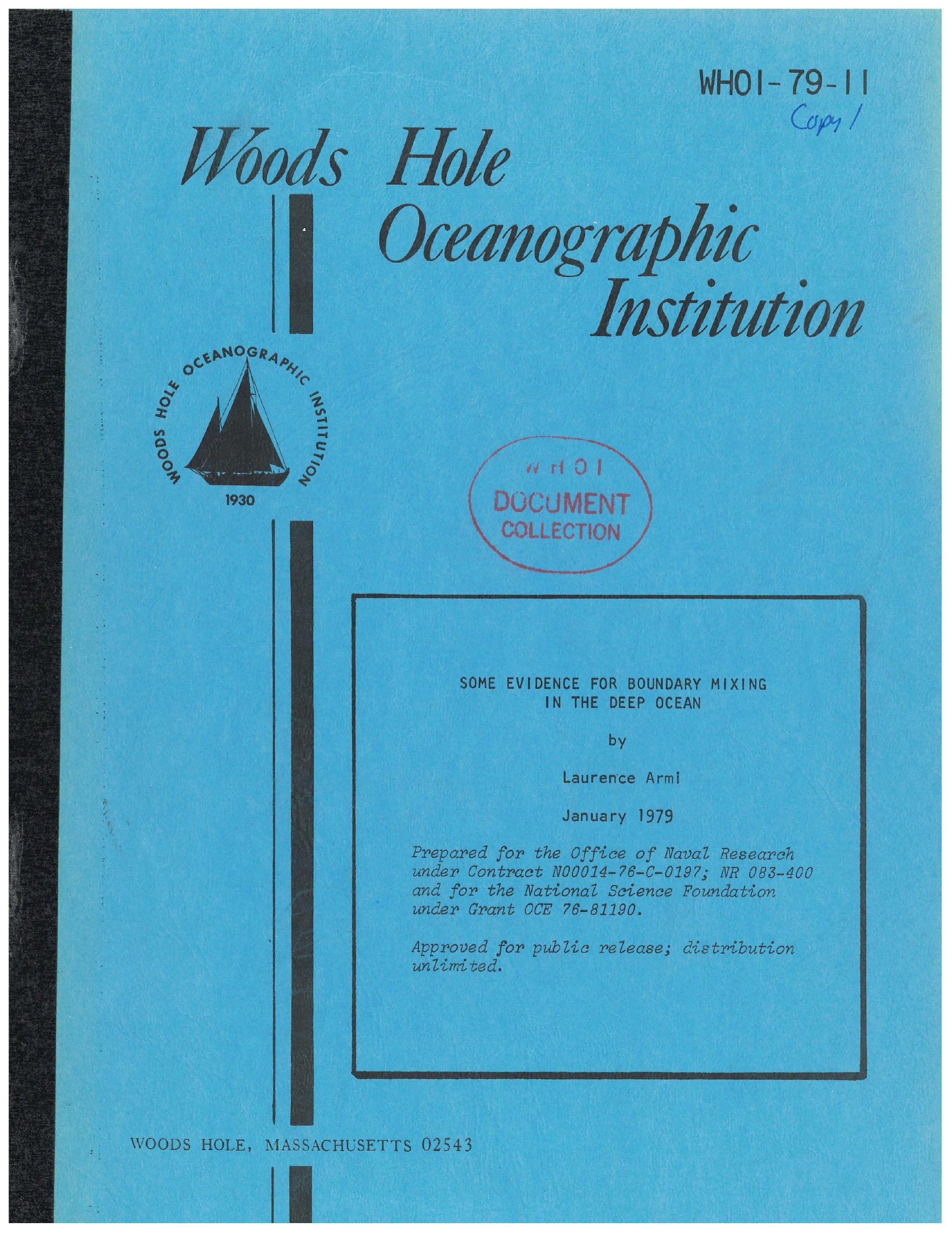


WHOI-79-11

SOME EVIDENCE FOR BOUNDARY MIXING

IN THE DEEP OCEAN

by

Laurence Armi

WOODS HOLE OCEANOGRAPHIC INSTITUTION

Woods Hole, Massachusetts 02543

January 1979

TECHNICAL REPORT

Prepared for the Office of Naval Research under Contract N00014-76-C-0197; NR 083-400 and for the National Science Foundation under Grant OCE 76-81190.

Reproduction in whole or in part is permitted for any purpose of the United States Govermment. In citing this report in a bibliography, the reference given should be to "Joumal of Geophysical Research, Vol. 83, No. C4, April 20, 1978, pp. 19711979".

Approved for public release; distribution unlimited.

Approved for Distribution: Valentine Worthington, Chairman Department of Physical Oceanography 


\title{
Some Evidence for Boundary Mixing in the Deep Ocean
}

\author{
Laurence Armi
}

Woods Hole Oceanographic Institution, Woods Hole, Massachusetts 02543

\begin{abstract}
Profiles of salinity and potential temperature in the deep ocean are presented which suggest the characteristic signature of two complementary mixing processes: vertical mixing within $\sim 50$-m-thick layers at boundaries and topographic features and lateral advection and eventual smearing of these mixed layers along iopycnal surfaces. The combined effect of these two processes is often parametrically disguised as a vertical eddy diffusivity in one-dimensional models. An estimate shows that the two processes can account for all the vertical mixing in the deep ocean without any vertical diffusion in the interior.
\end{abstract}

\section{INTRODUCTION}

Vertical distributions of water mass properties in the deep ocean are often not inconsistent with simple models involving a constant upward vertical velocity of $\sim 1-4 \mathrm{~cm} /$ day and a constant vertical eddy diffusivity of $\sim 1 \mathrm{~cm}^{2} / \mathrm{s}$ [cf. Stommel, 1958; Robinson and Stommel, 1959, Stommel and Arons, 1960; Munk, 1966]. A summary of these so-called 'thermocline' models has been given by Veronis [1969]. Recently, vertical eddy diffusivities have also been calculated by Sarmiento et al. [1976] for the deep ocean by using a one-dimensional model which ignores horizontal transport, vertical advection, and horizontal mixing relative to vertical mixing. One result of such a model is the establishment of an apparent relationship between vertical eddy diffusion and the inverse buoyancy gradient. The magnitude of the diffusivities found by Sarmiento et al. ranges from 0.6 to $440 \mathrm{~cm}^{2} / \mathrm{s}$ with typical values of about 10 $\mathrm{cm}^{2} / \mathrm{s}$.

Munk [1966] has attempted to interpret the vertical eddy diffusivity from a variety of viewpoints: from mixing along the ocean boundaries, from thermodynamic and biological processes, and from internal tides. A preliminary attempt at modeling vertical eddy diffusion along the lines proposed here, considering lateral circulation as well as boundary process, can be found in a note by Schiff [1966]. His model is a thermal convective flow in which strong horizontal flow occurs in thin layers close to the top and bottom. Unfortunately, his interior solution is isothermal.

In this paper, vertical profiles are presented which suggest that the existence of an apparent vertical, or in the context which follows, a cross-isopycnal eddy diffusivity, is the result of essentially two processes. The largest contribution to the cross-isopycnal mixing occurs within $\sim 50$ - to 150 -m-thick boundary mixed layers. The layers are then advected into the interior of the basin along their respective isopycnal surfaces. The signature of these layers is found near topographic features, whereas far in the interior of the basin the distinctive step structure is not as apparent. One is reminded of the arguments made by Iselin [1939], Montgomery [1938], and Rossby [1936] on the importance of the role of lateral turbulence and isentropic mixing for waters with surface characteristics. For the deep ocean we are suggesting that a similar combination of mechanisms is dominant. The theoretical and experimental investigation of these effects has only begun, and these data should be viewed as being preliminary.

Copyright (c) 1978 by the American Geophysical Union.
DATA

The profiles of salinity and potential temperature were all made with a Woods Hole Oceanographic Institution (W.H.O.I.)/Brown CTD microprofiler. The technical details, calibration techniques, and measurement accuracies are described and referenced by Armi and Millard [1976]. The complete instrument package also included a rosette sampler, a bottom sense switch, an acoustic pinger, a transponder for locating the package close to current meter moorings, and the Geosecs nephelometer. The data were taken during recovery and redeployment of Polymode Array 2 in October 1976 from the R/V Knorr. In Figure 1 the locations of the profiles are shown by station number along with the 1-day mean velocities measured at the deepest current meter $(4000 \mathrm{~m})$ near which the profiles were made (courtesy of W. Schmitz). Indicated by two concentric circles are the profiles shown in the remaining figures of this paper. All profiles are available on request from the author.

In Figures 2-7 profiles are shown of potential temperature (degrees Celsius), $\theta$, and salinity $S$ (per mil) versus pressure depth (decibars). By using the same scale for potential temperature as was used for the vertical profiles, salinity has also been plotted versus potential temperature as a superimposed $\theta-S$ scatter plot. The historical data of Worthington and Metcalf [1961] are also included on these $\theta-S$ plots. Inspection of the $\theta$ $S$ scatter plots shows the water mass properties of various mixed layers found in the vertical profiles. These mixed layers appear as regions dense in points on the $\theta$ versus $S$ plots; for example, at station KN 60/9 (Figure 3) the $\sim 150$-m-thick nearly uniform mixed layer centered at $5320 \mathrm{dbar}$ is represented by the dense region of points on the $\theta-S$ plot surrounded by a circle. The calibration of these water properties was fixed relative to the historical data of Worthington and Metcalf [1961] as described by Fofonoff et al. [1974]. The potential temperature was laboratory calibrated, and the salinity was assumed to be within $\pm 0.003 \%$ of the salinity found by Worthington and Metcalf [1961] at a potential temperature of $2.2^{\circ} \mathrm{C}$. The instrument resolution is $\sim 0.001 \%$ o in salinity, $0.0005^{\circ} \mathrm{C}$ in temperature, and $0.1 \mathrm{dbar}$ in pressure [Fofonoff et al., 1974]. This digitizing resolution has been significantly improved for the data shown in the figures by averaging over many points. On the $\theta$ versus $S$ plots each point is averaged over 15 data points; e.g., the collection for the mixed layer centered at about 5320 dbar at KN 60/9 (Figure 3) represents about 5000 data samples. The mixed layer found at KN 60/9 (Figure 3 ) and the layers of warmer saltier water found be- 


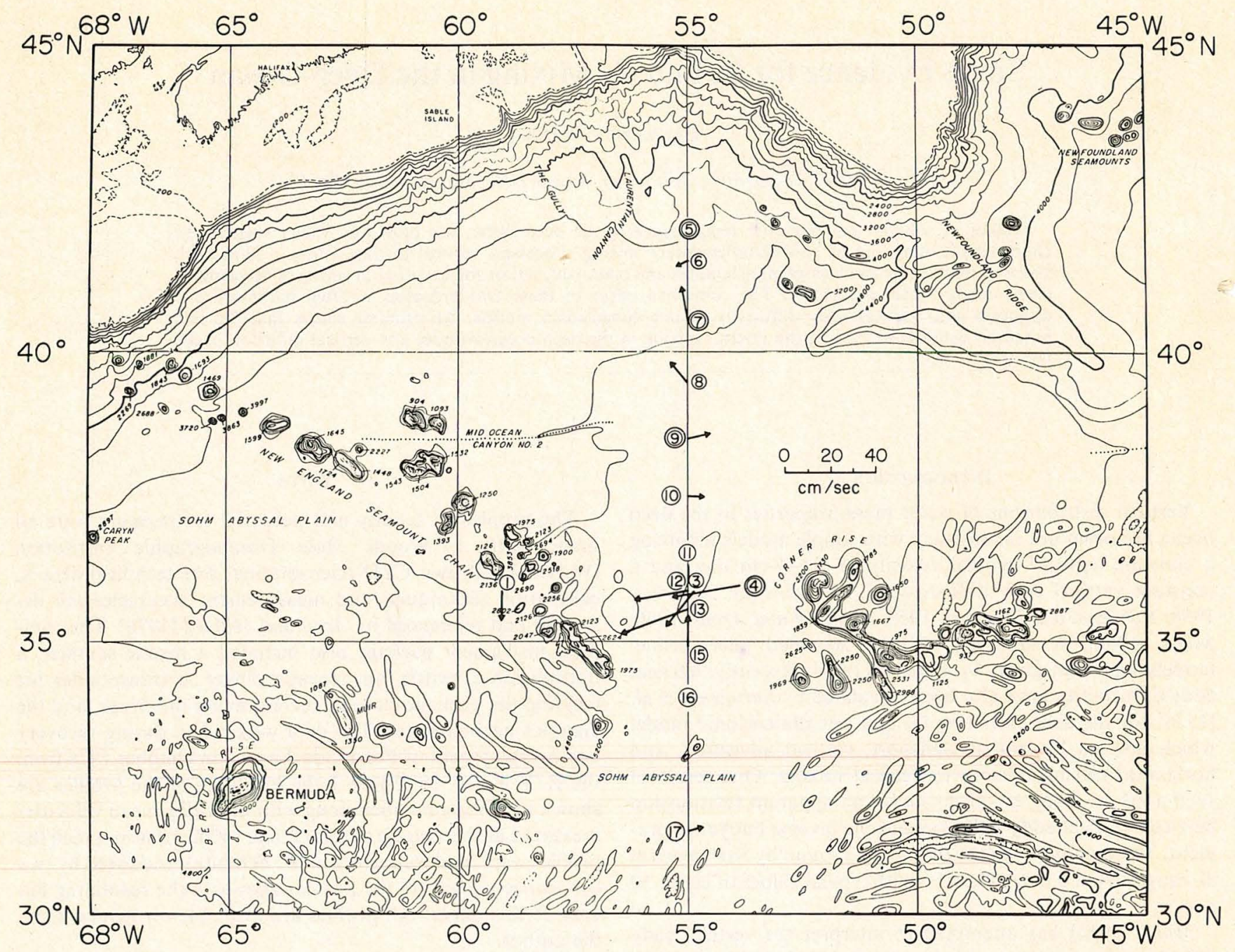

Fig. 1. Locations of CTD stations made in October 1976 on Knorr 60 cruise to recover and reset Polymode Array 2. The 1-day averaged current speeds and directions from the day previous to each CTD lowering are indicated (courtesy of W. Schmitz). The bottom profiles made at stations KN 60/4,60/5, 60/7, and 60/9 are discussed in this paper and are indicated by two concentric circles on the chart. Topography is from Uchupi [1971].

neath colder fresher water at $\mathrm{KN} 60 / 5$ shown in $\mathrm{KN} 60 / 5$ (Figure 7) are examples of anomalous layers that can be seen from inspection of the superposed $\theta-S$ plots. We are not immediately concerned with absolute deviations from the data of Worthington and Metcalf [1961] shown in the figures; it is the relative deviations with which we will be concerned here.

For KN 60/4 (Figure 2) an uncalibrated vertical profile of light scattering measured with the nephelometer in arbitrary Nephels units, $N_{e}$, is shown. Higher scattering is represented by a higher value of the arbitrary units; the signal does not fall to zero where it is not shown; unfortunately, it dropped out of the range of the digitizer because of instrumental difficulties.

\section{Discussion}

Layered structure. The profile taken at station KN 60/4 (Figure 2) differs from most profiles on an abyssal plain. It does not exhibit uniform stratification above the bottom mixed layer as some of the profiles of Armi and Millard [1976, Figures $1,2 b, 2 c$, and $4 b$ ] for the Hatteras Abyssal Plain do. This profile should also be contrasted with the upper parts of the profiles shown at stations KN 60/9 (Figure 3) and KN 60/ 7 (Figure 4) taken on the Sohm Abyssal Plain. It is the clarity of the multiple-step structure at station KN 60/4 (Figure 2) which we wish to emphasize as being atypical. Each of the layers is nearly homogeneous to within $\sim 0.002^{\circ} \mathrm{C}$ in potential temperature. As indicated on the $\theta-S$ scatter plot, none of the layers are anomalous in character in relation to one another. It appears as though an existing linear stratification has been mixed into layers.

When this profile was taken, at the nearby $4000-\mathrm{m}$-depth current meter, a mean current of $30 \mathrm{~cm} / \mathrm{s}$ had persisted for 6 days to the west. The profile was thus taken $\sim 100 \mathrm{~km}$ downstream of the Corner Rise to the east. The layered structure could have formed as the water was in contact with the Corner Rise. In that case it is possible that we are seeing the approximately 3-day-old advected signature of bottom mixed layers formed at various depths on the Corner Rise.

Armi and Millard [1976] and Armi [1977] discuss preliminary ideas on the dynamics of bottom mixed layers. The vertical extension of these individual layers appears to be limited not by the turbulent Ekman layer scale but by a scale set by the internal Froude number of the mixed layer. For a flat bottom the critical internal Froude number was found to be $F \sim 1.7$ and for sloping topography, $F<1.7$. A typical layer $100 \mathrm{~m}$ in height found at station KN 60/4 (Figure 2) could have been generated with a velocity near the bottom of $\sim 10$ 


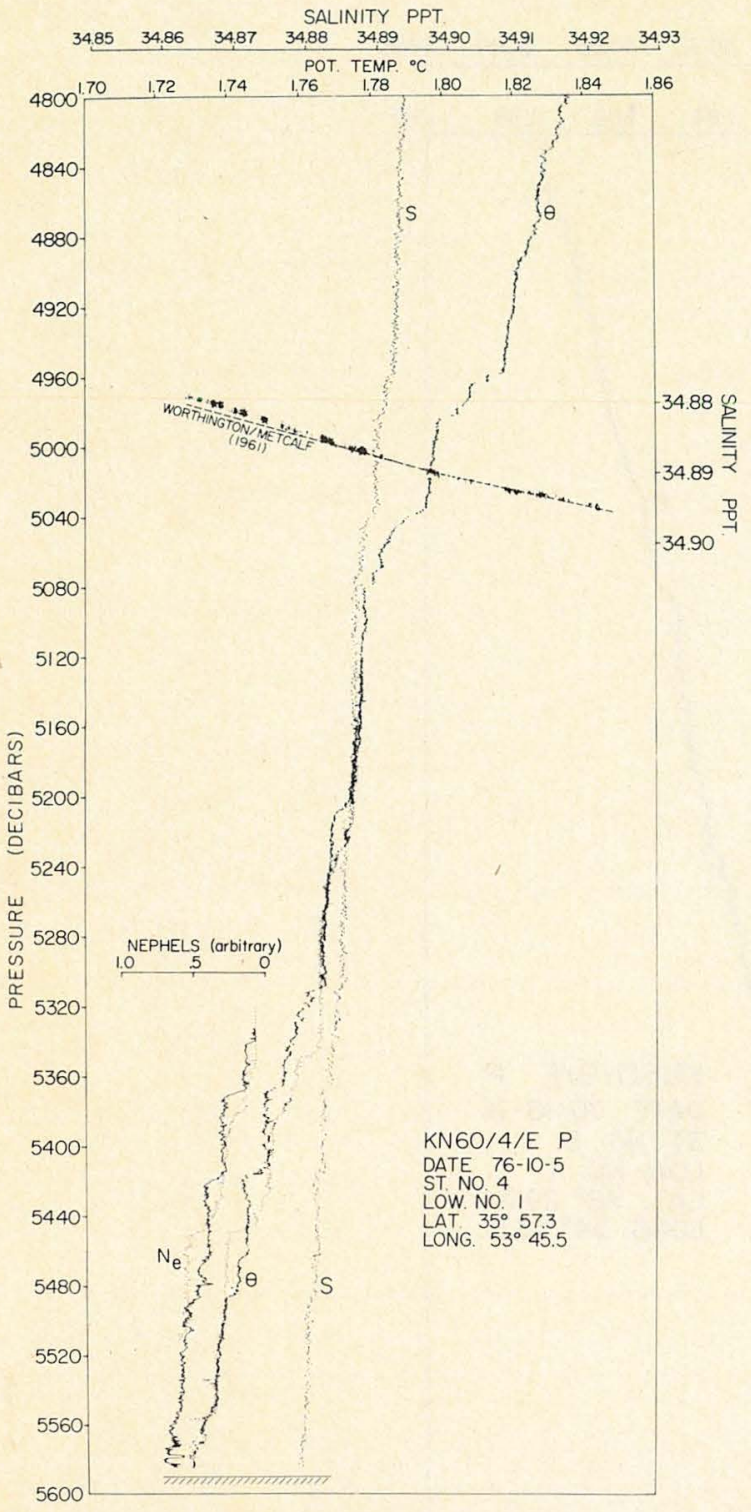

Fig. 2. Profile taken at station KN 60/4 (refer to.Figure 1) downstream of the Corner Rise. Shown are potential temperature $\theta$, salinity $S$, and light scattering $N_{e}$ versus pressure depth. Also superposed is a scatter plot of potential temperature versus salinity which includes the historical data of Worthington and Metcalf [1961]. The multiple layers are due to advection of mixed layers formed at their respective isopycnal depths on the Corner Rise. The water mass in each layer has the same characteristic as the background water mass. Both down and up traces of potential temperature and light scattering are shown; the up traces are dotted and only shown below 5200 dbar. Light scattering is shown increasing to the left to emphasize similarity with potential temperature and salinity traces.

$30 \mathrm{~cm} / \mathrm{s}$ (refer to Figure $3 b$ of Armi and Millard [1976]. This compares well with the velocity measured at the location of profile KN 60/4 (Figure 2) and other velocities shown for the Sohm Abyssal Plain region in Figure 1. The flow is thus energetic enough to have mixed these layers. As the flow moves by the Corner Rise, these layers presumably detach and are then carried into the interior. The layers are distinct at the location of station KN 60/4 only 3-4 days downstream of the Corner Rise, $100 \mathrm{~km}$ away. Similar step structures are also evident in the near-surface $800-\mathrm{m}$ depth profiles of Wunsch [1970, 1972]. He shows a systematic change in the temperature gradient as measured with a STD as the Bermuda Islands are approached and suggests the possibility that the stirring mechanism is the breaking of internal waves.

The profiles made as the package was both lowered and raised are shown for station $\mathrm{KN} 60 / 4$ (Figure 2). The character of the profile obtained as the package was raised was identical, i.e., multiple layers were again found. However, as the profiler got above the first bottom layer, the numbers and locations of the layered structures were found to be different. For example, instead of the three-step structure found on the way down between 5300 and 5500 dbar, only two larger steps were found on the way up. In the approximately $20 \mathrm{~min}$ between crossing 5400 dbar on the way down and the subsequent crossing on the way up, advection of $30 \mathrm{~cm} / \mathrm{s}$ can alone account for a Lagrangian spatial separation of $\sim 400 \mathrm{~m}$. The structures found a few hundred meters above the bottom have limited horizontal extent.

The included nephelometer shows that the light-scattering profile has a structure nearly identical to that of the salinity and potential temperature profiles. The small 1- to 2- $\mu \mathrm{m}$ particles, the concentration of which the nephelometer is most sensitive to, have a very slow settling rate of $\sim 10 \mathrm{~m} / \mathrm{yr}$ [cf. McCave, 1975]. For the advective processes with which we are dealing here they are essentially passive tracers. It appears as though the particulate matter was also mixed, to form the various nepheloid layers seen, from a background gradient of particulate matter just as the potential temperature and salinity were. If the material had been resuspended from the bottom at the depths on the Corner Rise where the mixed layers were formed, the concentration in each layer would be a function of the amount of locally resuspended material; in contrast, the concentration appears predetermined by the background gradient, and little local resuspension has occurred.

Water mass anomalies. Some profiles made along $55^{\circ} \mathrm{W}$ show an anomalous water mass at a potential temperature between 1.80 and $1.81^{\circ} \mathrm{C}$. This anomaly is evident in the profile made at station KN $60 / 9$ (Figure 3 ) as the 150 -m-thick layer sandwiched between the uniform stratification above and the bottom mixed layer below. This bottom layer and the stratification above lie on a straight $\theta$ versus $S$ characteristic, parallel to the Worthington and Metcalf [1961] characteristic shown. The anomalous layer sandwiched between is $\sim 0.0015 \%$ saltier than the background water mass would be at the same potential temperature of $1.81^{\circ} \mathrm{C}$.

The anomalous layer found at station $\mathrm{KN} 60 / 9$ is seen at the same potential density $\left(\sigma_{4}=45.96\right)$ as the bottom layer at station KN $60 / 7$ (Figure 4 ). The anomaly is due to a higher concentration of water with Norwegian Sea water characteristics [cf. Worthington, 1976]. Similar anomalous water was seen in the Geosecs station 28 profile [Bainbridge et al., 1976] at $39^{\circ} 0.0^{\prime} \mathrm{N}, 43^{\circ} 59.0^{\prime} \mathrm{W}$ near the bottom of the submarine canyon to the east.

Recently, in August 1977, similar anomalous water was also found on an R/V Oceanus cruise at station OC 31/1 (Figure 5) over the northern Hatteras Abyssal Plain. The nephelometer used on this cruise was of a new type developed at Woods Hole. It measured forward angle $\left(\sim 6-8^{\circ}\right)$ scattered light from a collimated white light source. This profile, as well as those of Figure 6, was added to the paper because it illustrates the persistence of the thin anomalous layer over large distances and long times; at $31^{\circ} 43.8^{\prime} \mathrm{N}, 70^{\circ} 44.9^{\prime} \mathrm{W}$, station OC $31 / 1$ was to the west of the area included in the map shown in Figure 1. The profile illustrates the usual well-mixed bottom 


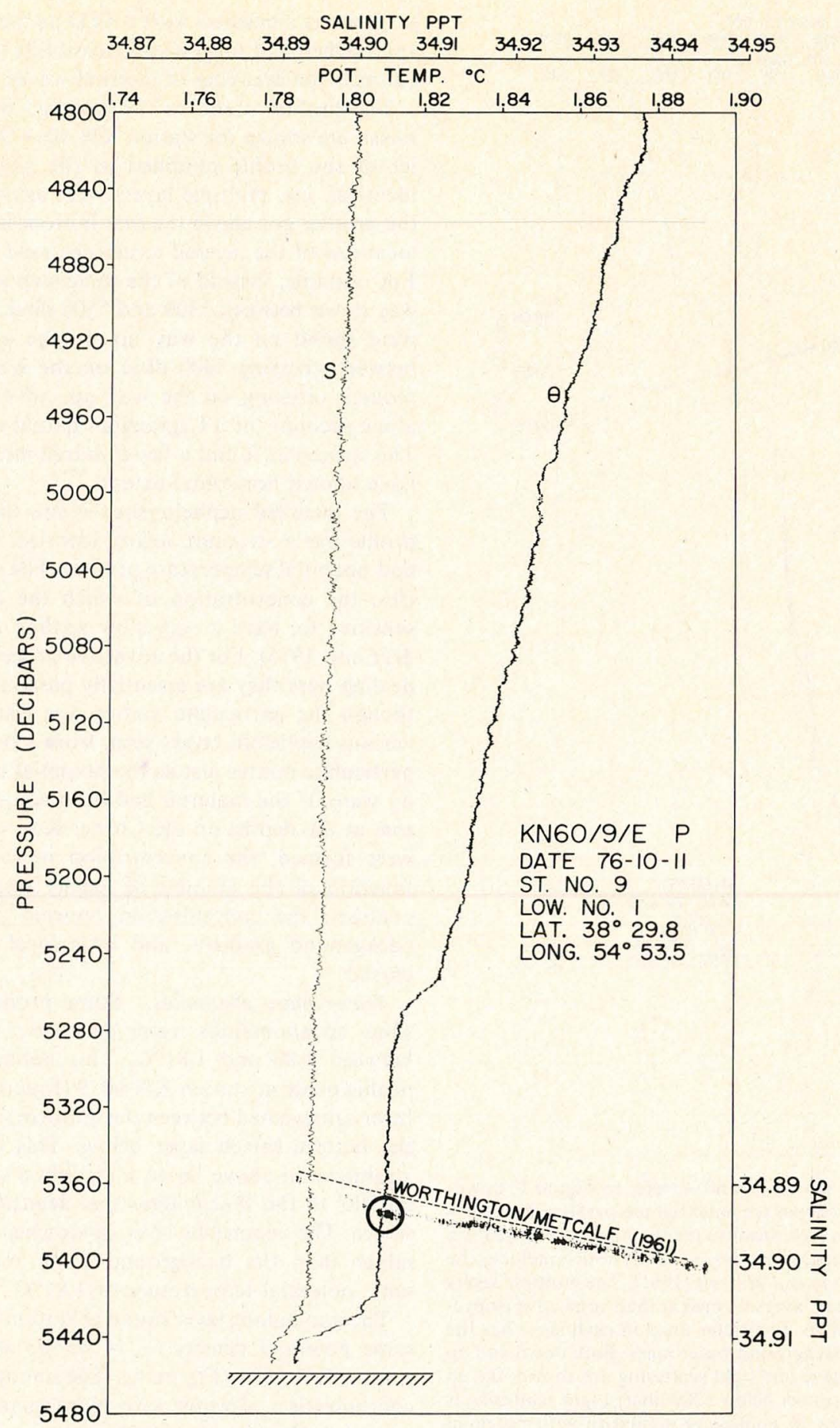

Fig. 3. Profile taken at station $\mathrm{KN} 60 / 9$ (refer to Figure 1 for location and Figure 2 for explanation of symbols). Two layers are evident, and the bottom layer has the same $\theta-S$ characteristics as the background water mass. The layer above is anomalous and has the same in situ potential density as the bottom layer found at station KN $60 / 7$ (Figure 4).

layer as well as many intrusions or advected features defined by mid-water maxima in light scattering. Of particular importance is the mid-water maximum at $5240 \mathrm{dbar}$. This water is anomalous in potential temperature and salinity (warm water is found beneath cold water); the potential temperature of this layer, $1.81^{\circ} \mathrm{C}$, is the same as it is for the anomalous layer-seen earlier at station KN 60/9 (Figure 3).

For comparison, selected profiles of potential temperature taken during different years and separated by thousands of kilometers over the western North Atlantic are shown in Fig- ure 6. The profile of Geosecs station 28 [Bainbridge et al., 1976] shows the Norwegian Sea overflow water at the bottom near the submarine canyon at the northeastern end of the Sohm Abyssal Plain. The remaining three profiles show a similar anomaly over the central and southern Sohm Abyssal Plain (KN 60/14 and KN 66/76) and over the northern $\mathrm{Hat}$ teras Abyssal Plain (OC 31/1 and also Figure 5). This anomalous layer at $\sim 1.81^{\circ} \mathrm{C}$ is apparently patchy; it is not always as vividly evident as shown in the profiles included in Figure 6. Only profiles which illustrate the layer by a clear anomalous 
signal in potential temperature (warm water beneath colder water) were chosen. The pressure depth scales have been displaced relative to each other to facilitate comparison.

Even stronger anomalies are found in the deep water at the most northern station along $55^{\circ} \mathrm{W}$, station $\mathrm{KN} 60 / 5$ (Figure 7). These anomalies are also seen at stations further to the south, although not as vividly. Anomalies found away from boundaries within the deep ocean are presented here as evidence for lateral advection by mesoscale eddies and the general circulation of the basin. Deep water mass sources do not appear to mix directly into the background water mass; instead, an anomaly is advected along its isopycnal surface. It is difficult in the absence of an interior source of anomalous water to explain these anomalies except by lateral advection. Other accounts of laminated structure include those by Stommel and Federov [1967], Gregg and Cox [1972], and Howe and Tait [1972]. It is believed that this is the first account of such a structure involving the Norwegian Sea water anomaly.

Lateral advection has been included in some models which attempt to estimate vertical and horizontal eddy diffusivities.

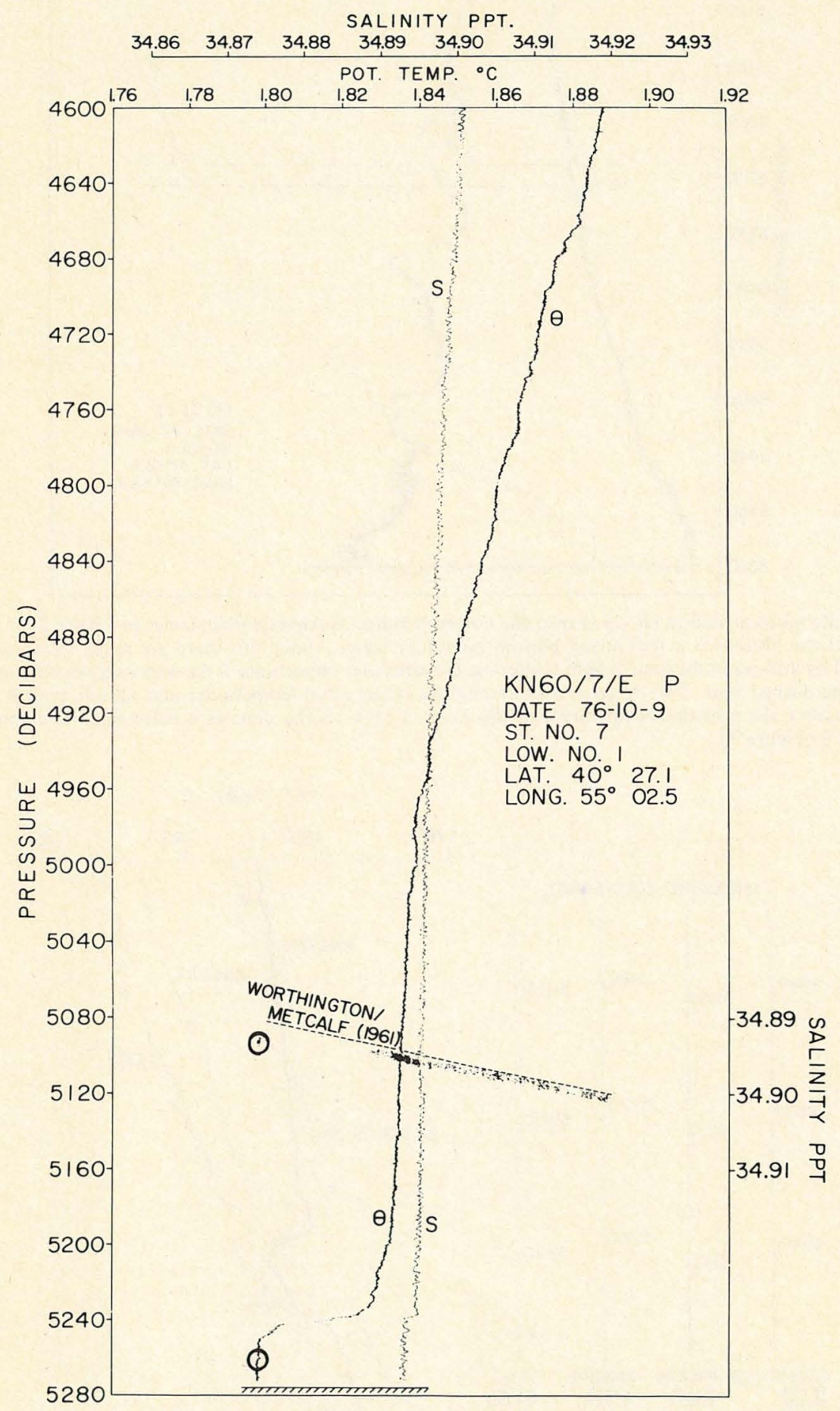

Fig. 4. Profile taken at station KN 60/7 (refer to Figure 1 for location and Figure 2 for explanation of symbols). The bottom mixed layer is anomalous at this location and contains a higher concentration of water with Norwegian Sea water characteristics than the background water mass above the layer. 


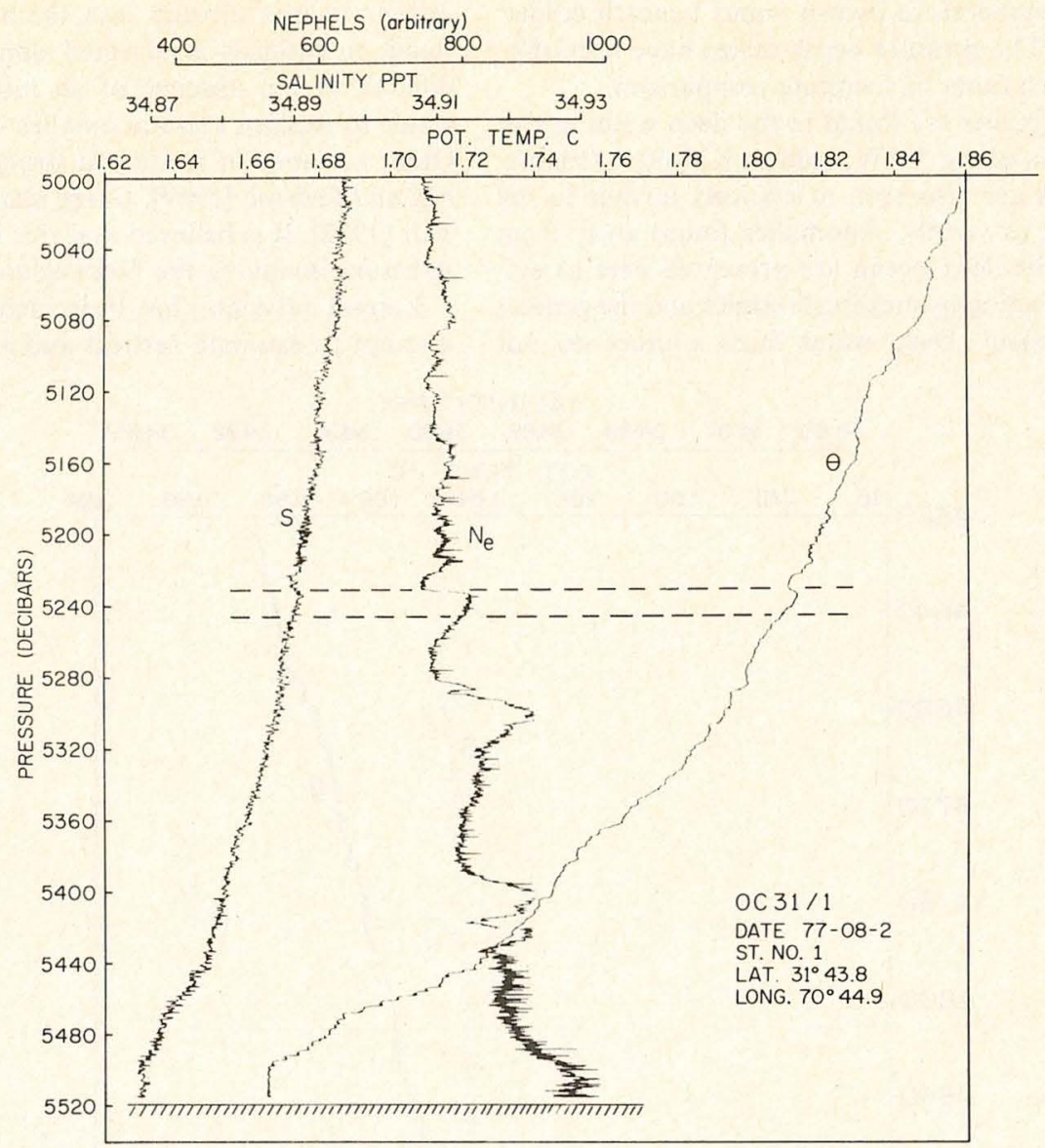

Fig. 5. Profile taken at station OC $31 / 1$ over the northern Hatteras Abyssal Plain (refer to Figure 2 for an explanation of symbols). At the bottom is a well-mixed bottom boundary layer. Above this there are many intrusions or advected features defined by mid-water maxima in light scattering. Of particular importance is the mid-water maximum at $5240 \mathrm{dbar}$. marked with the dashed lines. This water is also anomalous in potential temperature and salinity (warm water is found beneath cold water); the potential temperature of this layer, $1.81^{\circ} \mathrm{C}$, is the same as it is for the anomalous layer seen at station KN 60/9 (Figure 3).

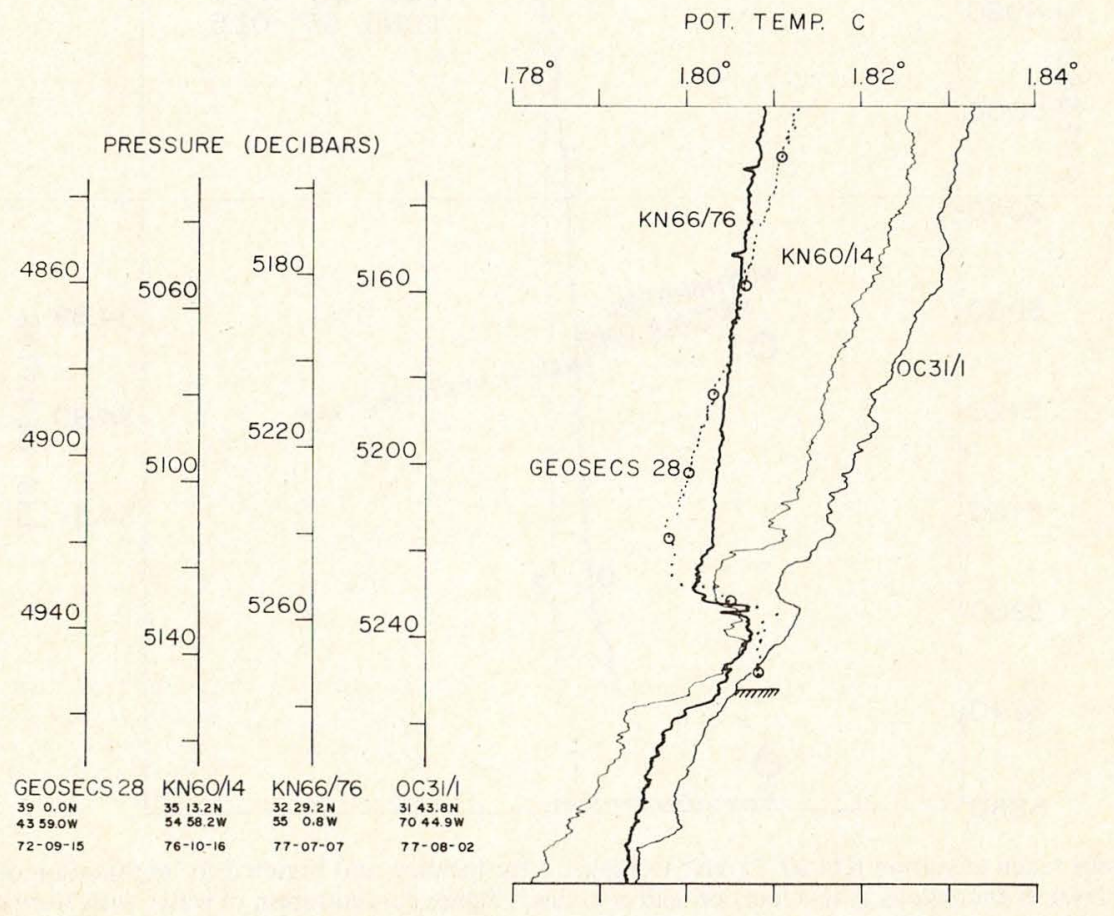

Fig. 6. Selected profiles of potential temperature from the western North Atlantic. These profiles show Norwegian Sea overflow water on the bottom at Geosecs station 28 [Bainbridge et al., 1976] and as a thin ( $20 \mathrm{~m}$ thick) layer at the other three stations. The pressure depth scales have been displaced relative to each other to facilitate comparison. 


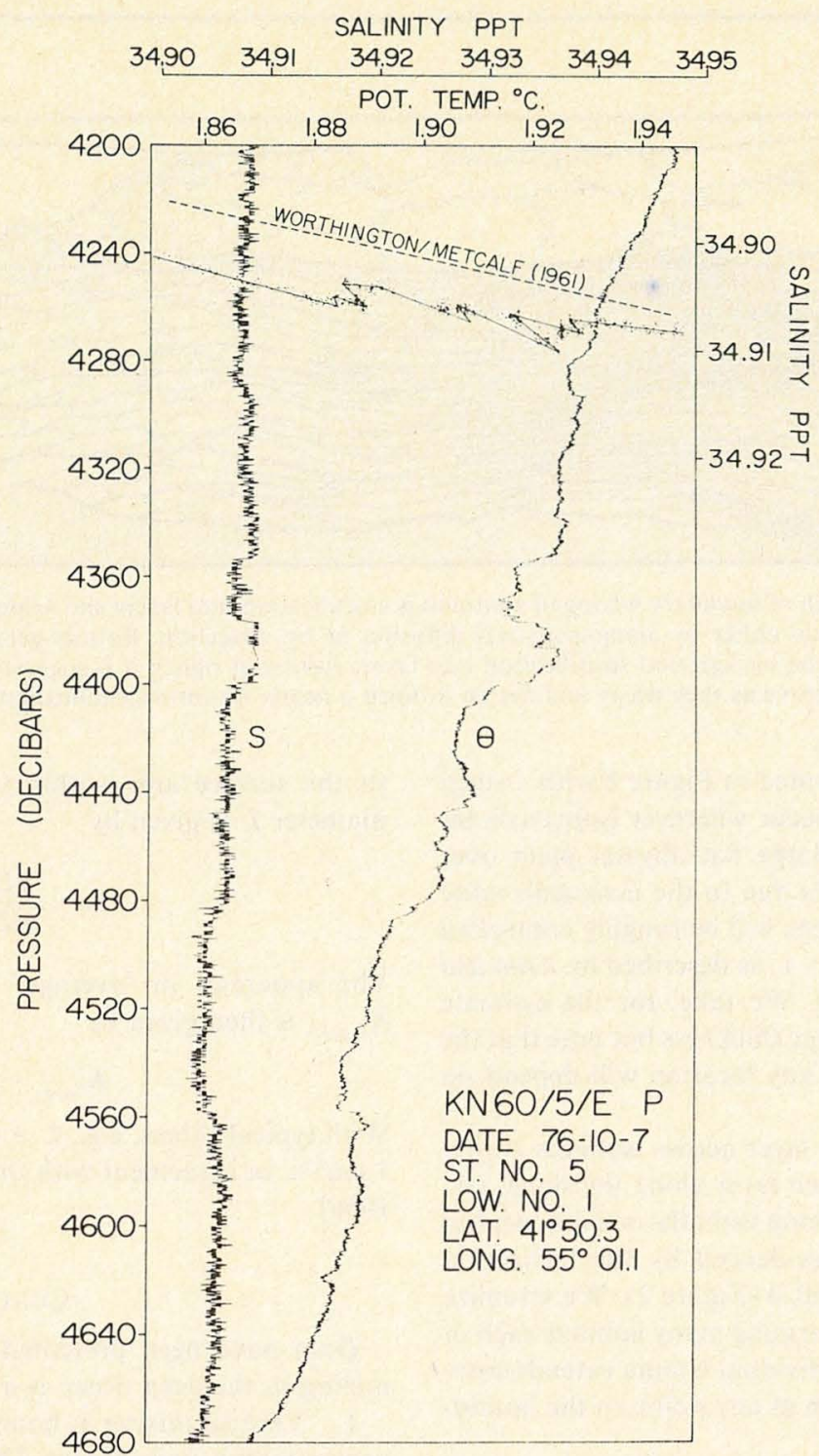

Fig. 7. Profile taken at station KN $60 / 5$ (refer to Figure 1, for location and Figure 2 for explanation of symbols). Many anomalous layers are shown of unknown origin, but most likely they are from the Norwegian Sea Basin. The profile is stable with regard to in situ potential density, although warm layers are found beneath colder water. The solid line on the $\theta$ $S$ plot connects the points as they lie on the vertical profile shown.

Rooth and Östlund [1972] use an empirical correlation between tritium concentration and temperature in the main thermocline to isolate diffusive effects from advective effects. Although Needler and Heath [1975] use a simple model which includes advection by a constant velocity and three-dimensional diffusion to obtain eddy diffusion coefficients for the Mediterranean high-salinity tongue, they point out that the apparent vertical and horizontal diffusion seen is difficult to separate, using their type of analysis, from diffusion along isopycnal surfaces, since such diffusion may appear as vertical diffusion when the surfaces are inclined. Also, Sarmiento et al. [1976] found that only 13 of approximately 25 profiles were suitable for their one-dimensional analysis. The remaining profiles were eliminated because of perturbations such as intermediate radon maxima, which they suggest may be due to eddies with a scale comparable to the spacing of the measurements $(>10 \mathrm{~m})$, pulses in the radon flux from the sediments, lateral diffusion of radon from neighboring topographic terraces, or bad data. Of these profiles with intermediate radon maxima, multiple-layer structure is often also indicated (cf.
Geosecs stations 66 and 78 [Bainbridge et al., 1976]). They may be the advected signature of past mixed layers once attached to the bottom.

\section{Vertical Mixing as a Combination of BOUNDARY Mixing AND A DVECTION}

The above results suggest a vertical mixing-advection model in which actual cross-isopycnal mixing takes place at basin boundaries and topographic features. A simplified conceptual sketch (Figure 8 ) illustrates boundary mixing of the continuous stratification into layers and the subsequent advection and diffusion of these layers along isopycnal surfaces.

Consider a circular basin surrounded by a boundary of slope $\alpha$. Suppose that mixed layers, each of approximate depth $h \sim 50 \mathrm{~m}$, form between density discontinuities, yielding a step structure similar to that described above. The topographic sites for boundary mixing must be steep or tall enough such that isopycnal surfaces actually intersect the topography, rather than simply deforming to the topographic shape, for the proposed model to be applicable. Although the boundary 


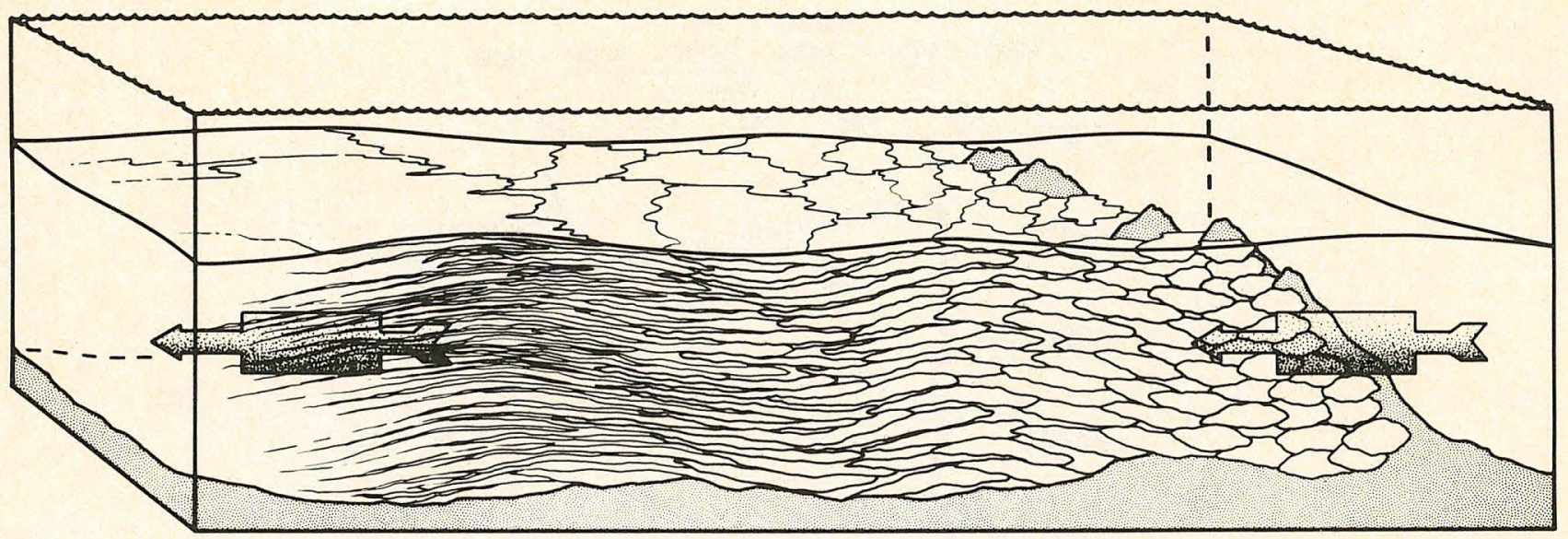

Fig. 8. Simplified sketch of boundary mixing of continuous stratification into layers and subsequent transport of mixed layers into interior of basin either by along-isopycnal diffusion or by advection. Bottom-generated turbulence due to motion of the water stirs the background stratification into layers (arrow at right); it is suggested that layers of different origins and densities interleave as they decay and flatten to form a nearly uniform stratification again (arrow at left).

mixing-advection model is illustrated in Figure 8 with a steep boundary, these processes may occur wherever isopycnals intersect the bottom, even on a large flat abyssal plain over which there exist isopycnal slopes due to the mesoscale eddy field. The depth of each of the steps will be roughly controlled by a Froude number criterion $F \sim 1$, as described by Armi and Millard [1976] and Armi [1977]. We take, for the estimate which follows, $\sim 50 \mathrm{~m}$ as an average thickness but note that the thickness of individual layers at any location will depend on the local velocity.

The horizontal extent of each layer across isobaths is presumed to be the projection of each layer along the slope, i.e., $\sim h / \alpha$. The extent of each layer along isobaths is unknown but is also presumably limited, as evidenced by the horizontal variability found at station $\mathrm{KN} 60 / 4$ (Figure 2). We visualize the boundary mixing process as forming many laminae each of approximately 50-m depth; no individual lamina extends completely around the basin, although at any point on the boundary one is always present.

We will estimate the vertical eddy diffusion within each layer at the boundary following Clauser [1956], i.e.,

$$
K_{v_{\text {bound }}} \sim \frac{1}{15} u_{*} h
$$

where $u_{*}$ is the friction velocity

$$
u_{*} \sim \frac{1}{30} U
$$

and $h$ is the height of the mixed layer; with a mean velocity, $U$ $\sim 10 \mathrm{~cm} / \mathrm{s}$, and $h \sim 50 \mathrm{m:} K_{v_{\text {bound }}} \sim 10^{2} \mathrm{~cm}^{2} / \mathrm{s}$. This estimate for the vertical eddy diffusivity at the boundary must be thought of only as a very rough estimate. In fact, Armi [1977] has pointed out that within the boundary mixed layer and above the Ekman layer scale, very little is known of the turbulence.

We also assume that the horizontal or along-isopycnal exchange is rapid. We do not understand how the character of the individual mixed layers formed at the boundaries is lost in the interior. One possibility is that layers of different origins and densities interleave as they decay and flatten. With enough interleaving a nearly uniform stratification may result.

The vertical or cross-isopyenal mixing at the boundary must serve the entire basin. We will equate the vertical transport at the boundary with the total transport represented as total area times the 'average' flux. The ratio of the surface area along the boundary for the mixed layers bounding any isopycnal surface to the surface area within the considered circular basin of diameter $L$ is given by

$$
A_{r} \sim \frac{\pi L h / \alpha}{\pi(L / 2)^{2}}=\frac{4 h}{\alpha L}
$$

The apparent, or 'average,' eddy diffusivity for the basin, $K_{v_{\text {basin }}}$, is then given by

$$
K_{v_{\text {basin }}} \sim K_{v_{\text {bound }}} \cdot A_{r}
$$

With typical values, e.g., $L \sim 4 \times 10^{3} \mathrm{~km}, \alpha=\frac{1}{200}$, and $K_{v_{\text {basin }}} \sim$ $1 \mathrm{~cm}^{2} / \mathrm{s}$, in agreement with the historical estimates [cf. Munk, 1966].

\section{CONCLUSION}

Data have been presented here to suggest that turbulent mixing in the deep ocean is a two-part process:

1. Vertical mixing at boundaries and topographic features occurs within finite layers. The vertical extent of the layers is limited by the stable background density field and the velocity of the flow which causes the boundary-generated shear and turbulence.

2. The layers formed are advected along constant density surfaces into the interior and eventually lose their step character.

The combined effect of these two processes may be parametrically disguised as a vertical eddy diffusivity in one-dimensional models. A crude estimate shows that the two processes can account for all the vertical eddy diffusion apparent in onedimensional models. The actual mechanism is far from a simple one-dimensional process. It involves complicated dynamics both at the boundary and in the interior about which we have much to learn.

Acknowledgments. I am very grateful for the assistance of the W.H.O.I. buoy group, Nan Bray, and Mary Raymer with the presentation of these results. The current speeds and directions shown in Figure 1 were provided through the courtesy of W. Schmitz. Trish Pettigrew carefully drew the conceptual sketch shown in Figure 8. This research is based on research supported by the Office of Naval Research under contracts N00014-76-C-0197 and NR 083-400 and by the National Science Foundation under grant OCE 76-81190. The suggestions from the reviewers and editor for improving the original manuscript are sincerely appreciated. This is contribution 4060 from the Woods Hole Oceanographic Institution, Woods Hole, Massachusetts. 


\section{REFERENCES}

Armi, L., The dynamics of the bottom boundary layer of the deep ocean, in Bottom Turbulence, Proceedings of the 8th International Liege Colloquium on Ocean Hydrodynamics, edited by J. C. J. Nihoul, Elsevier, New York, 1977.

Armi, L., and R. C. Millard, Jr., The bottom boundary layer of the deep ocean, J. Geophys. Res., 8I, 4983-4990, 1976.

Bainbridge, A. E., P. E. Biscaye, W. S. Broecker, R. M. Horowitz, G. Mathieu, J. L. Sarmiento, and D. W. Spencer, Atlantic Bottom Hydrography, Radon, and Suspended Particulate Atlas, Geochemical Ocean Sections Study, Scripps Institution of Oceanography, La Jolla, Calif., 1976.

Clauser, F. H., The turbulent boundary layer, Advan. Appl. Mech., 4. 1-51, 1956.

Fofonoff, N. P., S. P. Hayes, and R. C. Millard, Jr., WHOI/Brown CTD microprofiler: Methods of calibration and data handling, Ref. 74-89, Woods Hole Oceanogr. Inst., Woods Hole, Mass., 1974.

Gregg, M. C., and C. S. Cox, The vertical microstructure of temperature and salinity, Deep Sea Res., 19, 355-376, 1972.

Howe, M. R., and R. I. Tait, The role of temperature inversions in the mixing processes of the deep ocean, Deep Sea Res., 19, 781-791, 1972.

Iselin, C. O'D., The influence of vertical and lateral turbulence on the characteristics of the waters at mid-depths, Eos Trans. AGU, 414$417,1939$.

McCave, I. N., Vertical flux of particles in the ocean, Deep Sea Res., 22, 491-502, 1975.

Montgomery, R. B., Circulation in upper layers of southern North Atlantic, Pap. Phys. Oceanogr. Meteorol., 6(2), 1938.

Munk, W. H., Abyssal recipes, Deep Sea Res., 13, 707-730, 1966.

Needler, G. T., and R. A. Heath, Diffusion coefficients calculated from the Mediterranean salinity anomaly in the North Atlantic Ocean, J. Phys. Oceanogr., 5, 173-182, 1975.

Robinson, A., and H. Stommel, The oceanic thermocline and the associated thermocline circulation, Tellus, $11,295-308,1959$.

Rooth, C. G., and H. G. Ostlund, Penetration of tritium into the Atlantic thermocline, Deep Sea Res., 19, 481-492, 1972.
Rossby, C. -G., Dynamics of steady ocean currents in the light of experimental fluid mechanics, Pap. Phys. Oceanogr. Meteorol., 5(1), 1936.

Sarmiento, J. L., H. W. Feely, W. S. Moore, A. E. Bainbridge, and W. S. Broecker, The relationship between vertical eddy diffusion and buoyancy gradient in the deep sea, Earth Planet. Sci. Lett., 32 , $357-370,1976$.

Schiff, L. I., Lateral boundary mixing in a simple model of ocean convection, Deep Sea Res., 13, 621-626, 1966.

Stommel, H., The abyssal circulation, Deep Sea Res., 5, 80-82, 1958.

Stommel, H., and A. B. Arons, On the abyssal circulation of the world ocean, I and II, Deep Sea Res., 6, 140-154 and 217-233, 1960.

Stommel, H., and K. N. Federov, Small-scale structure in temperature and salinity near Timor and Mindanao, Tellus, 19, 306-325, 1967.

Uchipi, L., Bathymetric atlas of the Atlantic, Caribbean, and Gulf of Mexico, Ref. 71-72, Woods Hole Oceanogr. Inst., Woods Hole, Mass., 1971.

Veronis, G., On theoretical models of the thermocline circulation, Deep Sea Res., suppl., 16, 301-323, 1969.

Worthington, L. V., On the North Atlantic circulation, The Johns Hopkins Oceanographic Studies, no. 6, 110 pp., Johns Hopkins Press, Baltimore, Md., 1976.

Worthington, L. V., and W. G. Metcalf, The relationship between potential temperature and salinity in deep Atlantic water, Rapp. Proces Verb. Reunions Cons. Perma. Int. Explor. Mer, 149, 122-128, 1961.

Wunsch, C., On oceanic boundary mixing, Deep Sea Res., 17, 293$301,1970$.

Wunsch, C., Temperature microstructure on the Bermuda Slope with application to the mean flow, Tellus, 24, 350-367, 1972.

(Received May 11, 1977, revised October 27, 1977; accepted October 27, 1977.) 

MANDATORY DISTRIBUTION LIST

FOR UNCLASSIFIED TECHNICAL REPORTS, REPRINTS, AND FINAL REPORTS

PUBLISHED BY OCEANOGRAPHIC CONTRACTORS

OF THE OCEAN SCIENCE AND TECHNOLOGY DIVISION

OF THE OFFICE OF NAVAL RESEARCH

(REVISED NOVEMBER 1978)

1 Deputy Under Secretary of Defense

(Research and Advanced Technology)

Military Assistant for Environmental Science Room 3D129

Washington, D.C. 20301

Office of Naval Research

800 North Quincy Street

Arlington, VA 22217

3 ATTN: Code 483

1 ATTN: Code 460

2 ATTN: 102B

1 CDR J. C. Harlett, (USN)

ONR Representative

Woods Hole Oceanographic Inst.

Woods Hole, MA 02543

Commanding Officer

Naval Research Laboratory

Washington, D.C. 20375

6 ATTN: Library, Code 2627
12 Defense Documentation Center Cameron Station

Alexandria, VA 22374

ATTN: DCA

Commander

Naval Oceanographic Office NSTL Station

Bay St. Louis, MS 39522

1 ATTN: Code 8100

ATTN: Code 6000

ATTN: Code 3300

1 NODC/NOAA

Code D781

Wiscons in Avenue, N.W. Washington, D.C. 20235 

UNCLASSIFIED $\quad 1 / 79$

SECURITY CLASSIFICATION OF THIS PAGE (Whon Data Entered)

\begin{tabular}{|c|c|}
\hline REPORT DOCUMENTATION PAGE & $\begin{array}{c}\text { READ INSTRUCTIONS } \\
\text { BEFORE COMPLETING FORM }\end{array}$ \\
\hline $\begin{array}{l}\text { 1. REPORT NUMBER } \\
\text { WHOI-79-11 }\end{array}$ & 3. RECIPIENT'S CATALOG NUMBER \\
\hline \multirow{2}{*}{$\begin{array}{l}\text { 4. TITLE (and Subitie) } \\
\text { SOME EVIDENCE FOR BOUNDARY MIXING IN THE DEEP } \\
\text { OCEAN }\end{array}$} & $\begin{array}{l}\text { 5. TYPE OF REPORT \& PERIOD COVERED } \\
\text { Technical }\end{array}$ \\
\hline & $\begin{array}{l}\text { 6. PERFORMING ORG. REPORT NUMBER } \\
\text { WHOI CON. NO. } 4060\end{array}$ \\
\hline $\begin{array}{l}\text { 7. AUTHOR(s) } \\
\text { Laurence Armi }\end{array}$ & $\begin{array}{l}\text { 8. CONTRACT OR GRANT NUMBER(s) } \\
\text { NOOO14-76-C-0197; } \\
\text { OCE 76-81190 }\end{array}$ \\
\hline $\begin{array}{l}\text { 9. PERFORMING ORGANIZATION NAME AND ADDRESS } \\
\text { Woods Hole Oceanographic Institution } \\
\text { Woods Hole, MA } 02543\end{array}$ & $\begin{array}{l}\text { 10. PROGRAM ELEMENT, PROJECT, TASK } \\
\text { AREA Q WORK UNIT NUMBERS } \\
\text { NR } 083-400\end{array}$ \\
\hline \multirow{2}{*}{$\begin{array}{l}\text { 11. CONTROLLING OFFICE NAME AND ADDRESS } \\
\text { NORDA } \\
\text { National Space Technology Laboratory } \\
\text { Bay St. Louis, MS } 39529\end{array}$} & $\begin{array}{l}\text { 12. } \text { REPORT DATE } \\
\text { JanuarY } 1979\end{array}$ \\
\hline & 13. NUMBER OF PAGES \\
\hline \multirow[t]{2}{*}{ 14. MONITORING AGENCY NAME \& ADDRESS(if different from Controlling Office) } & $\begin{array}{l}\text { 15. SECURITY CLASS. (of thie roport) } \\
\text { Unclassified }\end{array}$ \\
\hline & $\begin{array}{l}\text { 15a. DECLASSIFICATION/DOWNGRADING } \\
\text { SCHEDULE }\end{array}$ \\
\hline
\end{tabular}

16. DISTRIBUTION STATEMENT (of this Ropost)

Approved for public release; distribution unlimited.

17. DISTRIBUTION STATEMENT (of the abotract ontered in Block 20, if different from Roport)

18. SUPPLEMENTARY NOTES

Reprinted from "Journal of Geophysical Research, Vol. 83, No. C4, April 20, 1978, pp. 1971-1979".

19. KEY WORDS (Continus on poverse side if noceseary and ldentlfy by block number)

1. Turbulence $\varepsilon$ diffusion

2. Boundary layer and exchange processes

3. Distribution and water masses

20. ABSTRACT (Continue on pevorae side If necoaeary and Identlfy by block number)

Profiles of salinity and potential temperature in the deep ocean are presented which suggest the characteristic signature of two complementary mixing processes: vertical mixing within $\sim 50-m-t h i c k$ layers at boundaries and topographic features and lateral advection and eventual smearing of these mixed layers along iopycnal surfaces. The combined effect of these two processes is often parametrically disguised as a vertical eddy diffusivity in one-dimensional models. An estimate shows that the two processes (Cont. on 
UL CI RITY CLASSIFICATION OF THIS PAGE(Whon Data Entered)

can account for all the vertical mixing in the deep ocean without any vertical diffusion in the interior.

SECURITY CLASSIFICATION OF THIS PAGE(When Data Entered) 


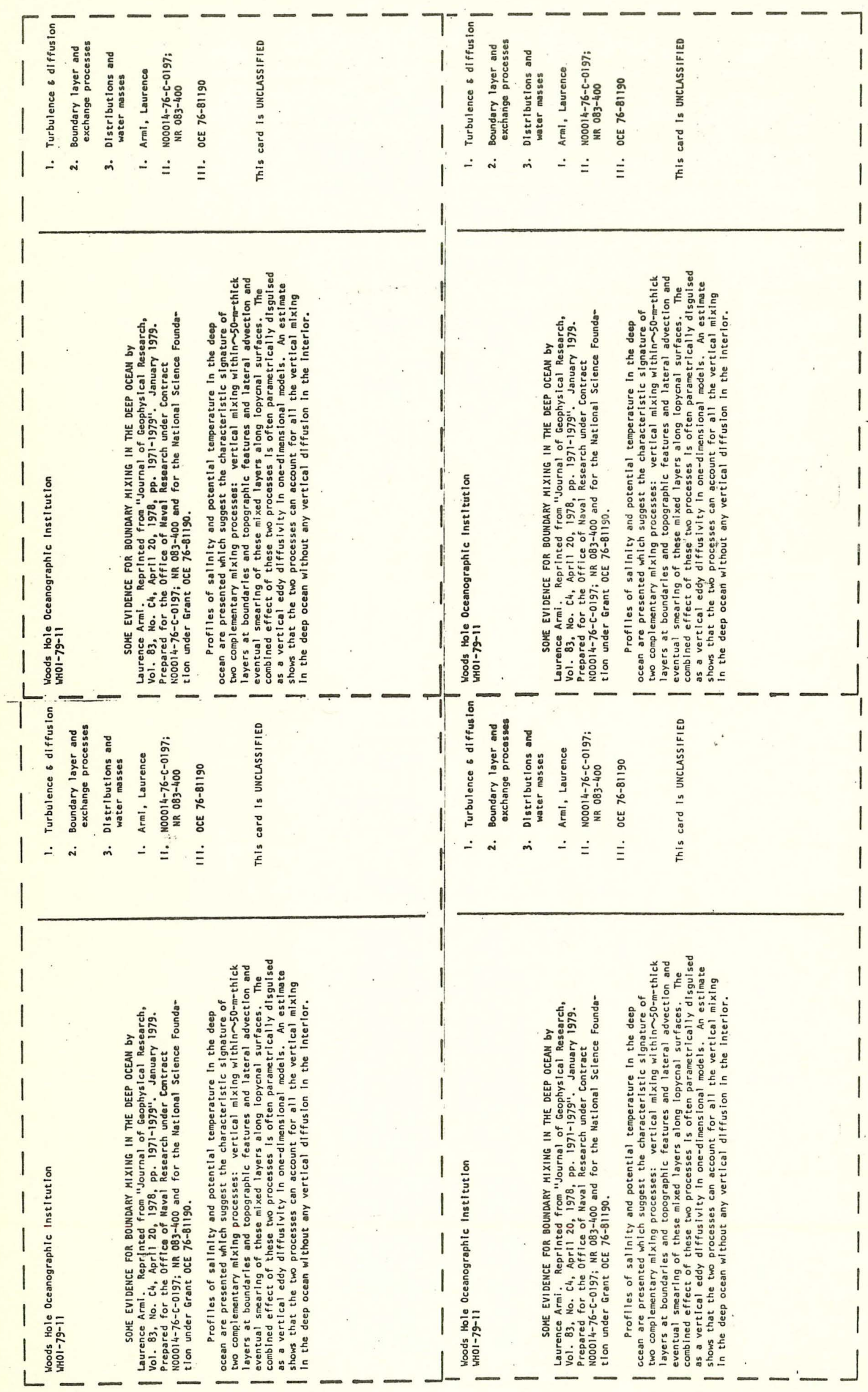

